\title{
Pay Geri Alım İlanlarının Hisse Getirisine Etkisi
}

\author{
Rifat KARAKUŞ * \\ İsrafil ZOR ** \\ Şeyma YILMAZ KÜÇÜK ${ }^{* * *}$
}

\section{ÖZET}

Bu çalışmanın amacı, şirketler tarafindan yapılan pay geri alım programlarına ilişkin bildirimlerin hisse getirisine etkisini belirlemektir. Bu amaca odaklanan çalışmada Borsa İstanbul'da işlem gören şirketlerin 2014-2016 yılları arasında pay geri alım programı başlatmasına ilişkin 100 adet bildirimin hisse getirilerine etkisi olay çalışması yöntemiyle incelenmiştir. Çalışma sonucunda, pay geri alım bildirimlerinin, bildirim tarihi öncesinde ve sonrasında istatistiksel olarak anlamlı kümülatif anormal getiriler yarattığ tespit edilmiştir. Ayrıca aktif büyüklüğüne göre ve piyasa değer/defter değerine göre ayrlan gruplar arasında bu ilişskinin farklılaştığl görülmüş̧ür.

Anahtar Kelimeler: Pay Geri Alımı, Hisse Getirileri, Anormal Getiri, Kümülatif Anormal Getiri, Olay Çalışmast.

JEL Sinıflandırması: G11, G12, G14.

\section{The Effect Of Stock Repurchase Program Announcements On Stock Returns}

\section{ABSTRACT}

The aim of this study is to determine the impact of share repurchase programs announcements made by companies on the stock return. In the study, the effect of 100 stock repurchase program announcements made by companies listed in Borsa Istanbul between 2014 and 2016 on stock returns are examined by event study method. As a result of the study, it was determined that the share repurchase announcements resulted in statistically significant cumulative abnormal returns before and after the reporting date. It is also seen that this relationship differs between the groups according to asset size and market value / book value.

Keywords: Stock Repurchase, Stock Returns, Abnormal Return, Cumulative Abnormal Return, Event Study.

Jel Classification: G11, G12, G14.

\footnotetext{
*Yrd. Doç. Dr. Rıfat Karakuş, Çankırı Karatekin Üniversitesi, İiBF, Bankacılık ve Finans Bölümü, ÇankırıTürkiye, rifatkarakus@karatekin.edu.tr

** Doç. Dr. İsrafil Zor, Kırıkkale Üniversitesi, İ̈BF, İşletme Bölümü, Kırıkkale-Türkiye, israfilzor@kku.edu.tr

*** Öğr. Gör. Şeyma Yılmaz Küçük, Çankırı Karatekin Üniversitesi, MYO, Finans, Bankacılık ve Sigortacıllk

Bölümü, Çankırı-Türkiye, seymayilmaz@karatekin.edu.tr
} 


\section{GİRiş}

Pay geri alımı belirli bir program çerçevesinde (belirli bir süre içerisinde, belirli bir fiyat aralığında ve belirli bir pay adedine kadar) bir şirketin kendi paylarını satın almasıdır. Şirketler, ihraç etmiş oldukları payları borsadan geri alabilirler, paylarını geri almak üzere ortaklarına yaptığı pay alım teklifleri ile çağrı yoluyla kendi hisselerinin alımını yapabilirler, ortaklarıyla yapacağı anlaşmalar çerçevesinde müzakere yoluyla gerçekleştirebilirler ve sentetik geri alım olarak da isimlendirilen türev işlemler aracilığıyla geri alım yapabilirler (Pirgaip, 2014). Şirketler tarafindan yapılan alımlar için en yoğun kullanılan yöntem borsadan alım olmaktadır. Şirketin kendi paylarını geri satın alma amacı bu payların daha sonra satılması olabileceği gibi bu payların iptal edilerek sermayenin azaltılması da olabilmektedir.

Pay geri alımları, şirketlerinin atıl nakitlerini değerlendirmek istemesi, paylarının olması gerekenin altında değerlendiğini düşünmesi, optimal kaldıraç seviyesini yani sermaye yapısını oluşturma amacı ve farklı bir şirket tarafından devralınmasının önlenmesi amacıyla gerçekleştirilebilir (Dittmar, 2000). Yine pay fiyatlarında yüksek volatilite oluşması, yatırımcılara şirket payları hakkında güven verme çabası, prestij kazanma isteği, temettü ödemesi yerine hisse senedi geri alımının şirketlerin vergi yükünü azaltması, ortağın şirkete olan borçlarının ödenmesi şirketleri pay geri alımına yönlendiren diğer nedenler olarak sıralanabilir (Gökgöz, 2014; Kaval, 2016). Ayrıca şirketler tarafından gerçekleştirilen türev işlemler sonucunda yatırımcılara hisse senedi verilmesinin gerekmesi durumunda payların geri alınarak bu yatırımcılara verilmesi sulandırma etkisini ortadan kaldırmaktadır (Kahle, 2002).

Şirketlerin kendi hisselerini geri almaları birçok avantajı beraberinde getirecektir. Şirket yöneticilerinin şirket faaliyetleri hakkındaki bilgilere yatırımcılardan daha hakim olmaları yani asimetrik bilgi nedeniyle pay geri alımı piyasa tarafından pay fiyatları için olumlu bir algı oluşturabilmektedir. Böylece ilgili şirketin paylarının değerinin artması, pay fiyatlarının volatilitesinin düşmesi, şirket hakkında yatırımcıların güveninin artması sağlanabilmektedir. Şirketler tarafından geri alınan payların iptal edilerek sermayenin azaltılması mümkündür. Şirketlerin iptal etmeden ellerinde bulundurdukları hisse senetlerinin ise muhasebeleştirilme şekli ülkeler arasında farklılıklar bulunmaktadır. Bu hisse senetlerinin varlık olarak raporlanmasına izin veren ülke mevzuatları bulunmakla birlikte Türkiye'de halka açık şirketlerde olduğu gibi Uluslararası Muhasebe Standartları'nı uygulayan işletmeler ancak özkaynaklardan indirim olarak raporlama yapabilmektedirler (Pirgaip ve Karacaer, 2015). Bu nedenle şirketlerin paylarını geri almaları kar payı dağıtımına bir alternatif olarak yatırımcılara fon aktarılması olarak değerlendirilmektedir. Şirketin paylarını geri alması sonucunda dolaşımdaki pay adedinin azalması söz konusu olacaktır. Şirketin pay sayısının azalması hisse başına karın artmasını dolayısıyla hisse fiyatının artmasını sağlayacaktır. Yine payların geri alımı sonucunda şirketin hem varlıklarının hem de özkaynaklarının azalması sağlanmış olacaktır. Bu da şirketin aktif ve özkaynak karlılığının artmasını sağlayacaktır. Yine şirketlerin hisse başına dağıtılan kar payının da sermaye azaltımından olumlu 
etkilenmesi söz konusu olacaktır. Dağıtılacak kar daha az hisse sayısına bölüneceğinden hisse başına kar payı yükselmiş olacaktır. Ayrıca hisse geri alımı şirketlerin atıl nakitinin azalmasını sağlayacağından yöneticilerin firma değerini olumsuz etkileyecek yatırım fırsatlarını değerlendirme imkanlarını sınırlandıracak, diğer bir ifade ile temsil maliyetlerini sorununu azaltacaktır (Grullon ve Michaely, 2004).

Pay geri alımı, şirketlerin temel amacı olan hissedar değeri maksimizasyonu açısından birçok avantaj sağladığından, bu yönteme olan ilgi artmıştır. ABD için temel endekslerden bir tanesi olan S\&P 500 endeksinde yer alan şirketlerden sadece 2016 yılının 3. çeyreğinde 362 şirket toplam 115.6 milyar \$ pay geri alımı gerçekleştirmiştir. S\&P 500 endeksinde yer alan şirketler tarafından yapılan pay geri alımları, alım sayısı yapan şirket sayısı ve toplam alım tutarları, çeyreklik dönemler itibariyle Şekil 1'de sunulmuştur. 2008-2009 küresel ekonomik kriz döneminde oldukça azalan pay geri alımlarının son dönemlerde tekrar önemli büyüklüklere ulaştığı görülmektedir. ABD’ye benzer şekilde Japonya, Kanada, Fransa, Almanya gibi gelişmiş ülkelerle birlikte Malezya, Güney Kore, Brezilya gibi gelişmekte olan ülkelerde de şirketlerin yoğun şekilde pay geri alım programları açıkladıkları bilinmektedir (Manconi, Peyer ve Vermaelen, 2014).

Şekil 1. Çeyrek Dönemlik Pay Geri Alımları (Milyon \$) ve Alım Yapan Şirket Sayıları

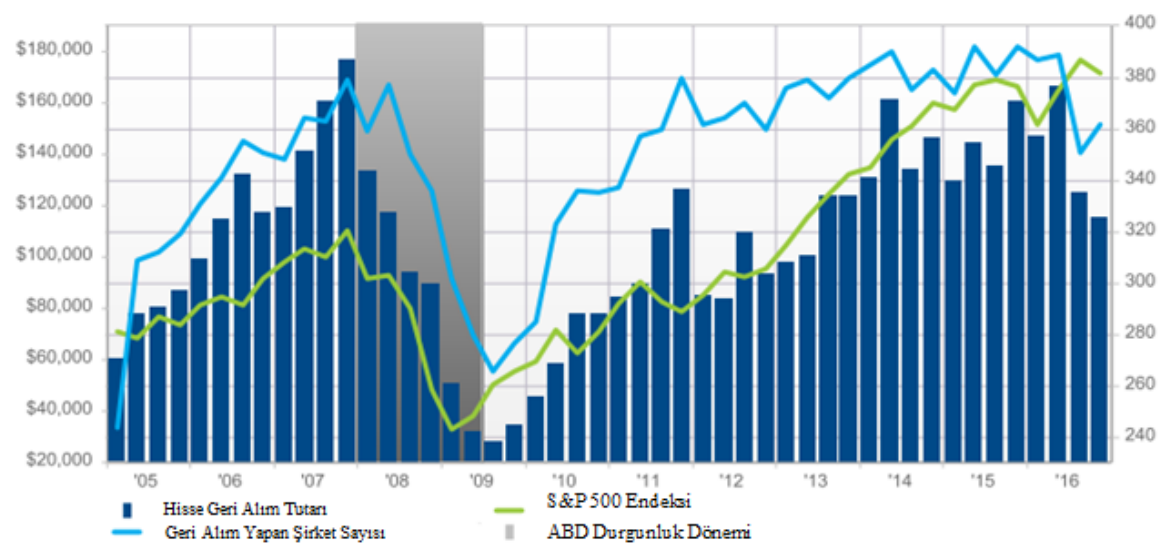

Kaynak: FactSet, 2016,

https://insight.factset.com/hubfs/Buyback\%20Quarterly/Buyback\%20Quarterly\%20Q3\%202016_12.19.pdf

Pay geri alımları şirketlerinin hisse senedi değerleri üzerinde önemli bir etkiye sahiptir. Bu çalışma da bu noktadan hareketle Borsa İstanbul'da pay geri alım programı açıklamalarının şirketlerin hisse senetlerinde anormal bir getiri yaratıp yaratmadığının tespitini amaçlamaktadır. Bu amaçla yapılan çalışmada öncelikle Türkiye'de pay geri alımı üzerinde durulmuş, bu konuya ilişkin literatüre yer verilmiş ve gerçekleştirilen uygulama ile pay geri alım programı ilanlarının hisse senetleri üzerinde anormal bir getiri sağlayıp sağlamadığ 1 analiz edilmiştir. 


\section{TÜRKIYY'DE PAY GERI ALIMI}

Birçok ülke piyasası için şirketlerin kendi paylarını geri satın almaları uzun bir geçmişe sahip olmasına rağmen Türkiye'de şirketlerin bu seçeneğe sahip olması ancak 2009 yılında başlamıştır. 1956 yılından 2011 yılına kadar yürürlükte olan 6762 sayılı Türk Ticaret Kanunu (TTK)'nun 329. maddesi şirketlerin kendi hisse senetlerini alamayacaklarını açıklamaktaydı. Ancak ilgili maddede açıklanan istisnai durumlarda şirketlerin kendi hisselerini satın almalarına izin verilmişti. Sermaye Piyasası Kurulu (SPK) 01.09.2009 tarih ve 27/748 sayılı İlke Kararı ile payları borsada işlem gören aracı kurumlar ve yatırım ortaklıklarının kendi hisselerini geri almalarına imkan sağlamıştır. Bu ilke kararının dayanağı 6762 sayılı TTK'nin 329. maddesinde düzenlenen, geri alım işlemlerinin esas sözleşmeye göre şirket konusuna giren işlemlerden olmasına yönelik istisna hükmü olmuştur. Böylece Türkiye'de ilk defa sınırlı da olsa şirketlerin kendi hisse senetlerini geri alması mümkün hale gelmiştir.

14.02.2011 tarihinde yayımlanan ve 01.07.2012 tarihinde yürürlüğe giren 6102 sayıl1 TTK, tüm anonim şirketlerin kendi paylarını almalarına belirli sınırlamalar çerçevesinde izin vermiştir. Söz edilen kanunun getirdiği yenilikle uyumlu şekilde, SPK 10.08.2011 tarih ve 26/767 sayılı İlke Kararı ile borsada işlem gören tüm şirketlerin paylarını geri alabileceğini düzenlemiştir. 6362 Sermaye Piyasası Kanun'nun 30.12.2013 tarihi itibarıyla yürürlüğe giren pay geri alımlarına ilişkin hükümleri ve bu hükümlere açıklık kazandıran 03.01.2014 tarih ve II-22.1 sayılı “Geri Alınan Paylar Tebliği” ile uygulamanın detayları tamamlanmıştır.

İlgili düzenlemelerde şirketlerin geri alınan paylarının nominal değerinin, daha önceki alımlar dahil ortaklıkların ödenmiş veya çıkarılmış sermayesinin yüzde onunu aşamayacağı hükme bağlanmıştır. Ancak 15 Temmuz 2016'da yaşanan darbe girişiminin piyasalarda yaratabileceği etkileri sınırlamak için SPK 21.07.2016 tarihinde yaptığı basın duyurusu ile ikinci bir duyuruya kadar şirketlerin özel durum açıklaması yapmak kaydıyla herhangi bir limit söz konusu olmaksızın borsada kendi paylarının geri alımını gerçekleştirebileceklerini açıklamıştır. Bu durum şirketler tarafindan yoğun ilgi görmüş ve 25 Temmuz itibariyle 35'i aşkın şirket kendi paylarında geri alım yapacaklarına ilişkin özel durum açıklaması yapmıştır. Bu çalışmada gerçekleştirilecek uygulama için Türkiye'de hisse geri alımının hukuki olarak altyapıya kavuştuğu 2014 ile 2016 yılları arasına ait veriler kullanılmıştır.

\section{LITERATÜR TARAMASI}

Şirketlerin kendi paylarını satın alması uygulaması Türkiye için son dönemlerde uygulamaya başlandığından Türkiye piyasasını konu alan çalışmaların sınırlı olduğu görülmektedir. Yurt dışı piyasalarda ise hisse geri alımının daha uzun dönemdir ve şirketler tarafından yoğun uygulanıyor olması bu alandaki çalışmalar için isteklendirici olmuş ve literatürde hisse geri alımlarının hisse fiyatı ile ilişkisini ve üzerindeki etkisini inceleyen önemli çalışmalar yer almıştır. 
Dann (1981), New York Menkul Kıymetler Borsası'nda işlem gören 122 şirkete ait 1962-1976 yılları arasında gerçekleştirilen 143 hisse geri alım çağrısını kullanarak gerçekleştirdiği çalışmasında, geri alım ilanının piyasa tarafından olumlu bir işaret olarak algılanmasının sonucunda bildirimin yapılmasından itibaren bir gün içerisinde hisse fiyatlarında anlamlı bir yükselme yarattığını kanıtlamıştır. Chang, Chen ve Chen (2010) 19862005 yılları arasında geri alım programı açıklayan 1741 Amerikan şirketine ait 5717 pay geri alım programı başlatma bildirimlerini kullanarak kısa dönemde bu bildirimlerin anormal getiri sağladığını, aynı zamanda bu şirketlerin uzun dönem fiyat performanslarının da bu bildirimlerden olumlu etkilendiğini tespit etmiştir. Lee, Ejara ve Gleason (2010) Fransa, Almanya, İtalya ve Birleşik Krallık'ta faaliyet gösteren şirketlere ait 1990-2005 yılları arasındaki 512 hisse geri alım programını kullandıkları çalışmalarında, bu programların hisse fiyatı üzerindeki etkisini ve programlara etki eden faktörleri incelemişlerdir. Olay çalışması ve Tobit regresyon analizinin kullanıldığı çalışma sonucunda Alman ve İtalyan geri alım programlarının Amerikan şirketlerine benzer şekilde pozitif ve anlamlı bir hisse fiyatı tepkisi yarattığı, İngiliz hisse senetlerinde anormal getirilerin daha düşük olduğu ve Fransız hisse senetleri için anormal getirilerin istatistiksel olarak anlamlı olmadığı görülmüştür. Yine Fransa, Almanya ve Birleşik Krallık piyasalarında hisse geri alım programı ilanlarına piyasa tepkisini ve kurumsal yapı ve yasal düzenlemelerin bu programlara etkisini inceledikleri çalışmalarında Andriosopoulos ve Lasfer (2015), ilk bildirimlerin $(-1,+1)$ olay penceresi içerisinde her üç piyasa içinde anlamlı ve pozitif anormal getiriler bulunduğunu belirtmiştir. $(+2,+20)$ olay penceresi içerisinde sadece Birleşik Krallık piyasası için anlamlı bir pozitif anormal getiri tespit edilmiş, $(-2,-20)$ olay penceresi için ise hiçbir piyasada anlamlı anormal getiri gözlemlenmemiştir. Su ve Lin (2012) 2000-2003 yılları arasında Tayvan'da işlem gören şirketler için geri alım programı ilanlarının bildirim tarihinden itibaren kısa süreli olarak anormal getiriye neden olduğunu, bu bildirimi yapan şirketlerin uzun dönemde herhangi bir anormal getiri yaratmadıklarını gözlemlemiştir.

Gelişmiş piyasalarda olduğu gibi gelişmekte olan piyasalarda da hisse geri alımının hisse değerine etkisini inceleyen çalışmalar yapılmıştır. Isa ve Lee (2014) Malezya piyasasında işlem gören şirketler tarafından yapılan hisse geri alımına ilişkin yönetim kurulu kararı bildirimleri, genel kurul onay bildirimleri ve hisse alımı gerçekleştirme bildirimlerinin tamamı için kısa dönemde anormal getiri elde edildiğini, ayrıca küçük şirketlerde anormal getirinin daha yüksek olduğunu tespit etmişlerdir. Albaity ve Said (2016) 2009-2010 y1lları arasında Malezya'da işlem gören 132 şirkete ait 221 açık piyasa geri alım programını örneklem olarak belirledikleri çalışmalarında, bu program ilanlarının hisse senetleri için uzun dönemde anormal getiri sağlayıp sağlamadığını araştırmışlardır. Gerek tüm veri seti için, gerek sadece küçük şirketler için, gerekse yüksek defter değeri/piyasa değeri oranına sahip şirketler için uzun dönemli istatistiksel olarak anlamlı anormal getiri olduğu tespit edilememiştir. Chatterjee ve Dutta (2015) Hindistan piyasasında işlem gören şirketlerin 20092013 yılları arasında yaptığı 95 hisse geri alım bildirimini inceledikleri çalışmalarında 
bildirimden 28 gün öncesi ve sonrasındaki dönemde anormal getirilerin ciddi bir büyüklüğe ulaşmadığını tespit etmişlerdir. Wesson, Muller and Ward (2014) 1999-2009 yılları arasında Güney Afrika piyasasında 69 şirket tarafından gerçekleştirilen 195 hisse geri alım programı bildiriminin gerçekleştirilmesinden önceki 3 aylık dönemde negatif kümülatif anormal getiri tespit edilirken, bildirim dönemi ve sonrasında anlamlı anormal getiri tespit edememişlerdir.

Diğer gelişmekte olan piyasalarda olduğu gibi şirketlerin kendi hisselerini geri almasının yasal olarak mümkün hale gelmesi Türkiye piyasasında da bu uygulamanın yaygınlaşmasını sağlamıştır. Uygulamada yer bulan bu durumun yeni olması yapılan akademik çalışmaların sınırlı olmasını beraberinde getirmiştir. Eyüboğlu ve Bulut (2015) borçlanmalar, borçların yapılandırılması, temettü ödemeleri, hisse arzı/satışı, hisse bölünmesi, derecelendirme kuruluşlarınca açıklanan finansal notlar ve kazanç açıklamaları gibi finansal bildirimlerin kısa dönemde anormal getiri sağlayıp sağlamadığını inceledikleri çalışmalarında hisse geri alım bildirimlerinin etkisini de incelemişlerdir. 2003-2012 yılları arasında BİST-30 endeksinde listelenen şirketler tarafindan yapılan 35 hisse geri alım bildiriminin incelenmesi sonucunda $(-10,+10)$ gün olay penceresi aralığında gerek bildirimden önce, gerekse bildirimden sonrası için farklı olay penceresi aralıklarında anlamlı kümülatif anormal getiriler tespit edilmiştir. Pirgaip (2014) pay geri alımının şirket paylarının likiditesini artırdığ oynaklığını düşürdüğü hipotezlerini sınadığı çalışmasında pay geri alımları sonrasında şirket paylarının fiyatlarındaki yükselmeye bağlı olarak anormal getiri elde edilip edilemeyeceğini incelemiştir. 2010/3-2013/12 döneminde Borsa İstanbul'da işlem gören ve pay alımı yapan 34 şirketin verileri ile gerçekleştirilen uygulama sonucunda, kısa vadede geri alım işlemleri sonrasında paylardan anormal getiri elde edilmesinin mümkün olduğu, payların likiditesinin arttığı ve oynaklığının da azaldığı tespit edilmiştir.

\section{VERI VE METODOLOJI}

\section{1. Çalışmanın Amacı ve Kapsamı}

$\mathrm{Bu}$ çalışma, Borsa İstanbul'da işlem gören şirketler tarafından yapılan pay geri alım programı bildirimlerinin şirketlerin hisse fiyatlarında nasıl bir etki yarattığını tespit etmek amacıyla gerçekleştirilmiştir. Şirketlerin pay alım programını genel kurul onayına sunacağına dair yaptığı ve genel kurul onayına sunulması gerekmeyen durumlarda yönetim kurulu kararı olarak paylaştığı pay geri alım bildirimleri belirlenerek, bu bildirimlerin yapıldığı tarih etrafındaki günlerde hisselerde anormal bir getiri ve belirli gün aralıklarında kümülatif anormal getiriler oluşup oluşmadığı incelenmiştir.

Borsa İstanbul'da işlem gören tüm şirketler, yatırımcı açısından önem arz eden durumları Kamu Aydınlatma Platformu (KAP) aracı̆̆ıyla kamuoyuyla paylaşmak durumundadır. Türkiye'de şirketlerin kendi hisselerini geri almaları ile ilgili yasal mevzuatın tamamlanması göz önünde bulundurularak 2014-2016 yılları arasında KAP aracıllı̆ııla yapılan pay geri alım programlarına ilişkin bildirimler taranmış ve toplam 100 bildirim tespit 
edilmiştir. Bu bildirimlerin 14 adedi 2014 yılına, 19 adedi 2015 yılına ve 67 adedi 2016 yılında gerçekleştirilmiştir. Türkiye piyasası için gerçekleştirilen diğer çalışmalara göre daha geniş bir veri setine sahip olması nedeniyle bu çalışmanın literatüre katkı sağlayacağı düşünülmektedir.

\section{2. Çalışmanın Yöntemi}

Çalışmada, olay çalışması yöntemi kullanılmıştır. Finans, muhasebe, yönetim, ekonomi, pazarlama gibi birçok disiplin için kullanılabilen bir yöntem olan olay çalışması, Dolly tarafından 1933 yılında ilk defa kullanıldığından bu yana birçok çalışmanın metodunu oluşturmuştur. Finans alanında olay çalışması, bir olayın firma değeri üzerindeki etkisini belirlemeye yarayan istatistiksel bir yöntem olarak kullanılmaktadır.

Olay çalışmasında öncelikle olayın gerçekleştiği tarihten belirli bir süre öncesi ve sonrasını ifade eden olay penceresi tanımlanmalıdır. Bu olay penceresi içerisinde her alan her bir gün için hisse senetlerinin gerçekleşen getirileri belirlenir. Ayrıca ilgili hisse senetleri için olay penceresi içerisinde beklenen getiriler tespit edilir. Gerçekleşen getirilerin beklenen getirileri aşan kısmı anormal getirileri ifade etmektedir. Olay penceresi içerisinde toplam anormal getiriler kümülatif anormal getirileri oluşturmaktadır. Anormal ve kümülatif anormal getirilerin istatistiksel olarak anlamlılığı $\mathrm{t}$ testi ile analiz edilerek bu getirilerin tesadüfi olup olmadığı incelenmektedir.

Çalışmada olayı ifade eden şirketler tarafından pay geri alım programı başlatılmasına ilişkin yapılan bildirimler oluşturmaktadır. Bildirimlerin yapıldığı tarihten 10 gün öncesi ve sonrası ise çalışmanın olay penceresi olarak kabul edilmiştir. Pay geri alım programı başlatacağına ilişkin bildirimde bulunan her bir şirket için olay penceresi içerisindeki günlerde ilgili şirketin hisse senedinin anormal getirileri, denklem 1'e göre hesaplanmıştır.

$$
\mathrm{AR}_{\mathrm{it}}=\mathrm{R}_{\mathrm{it}}-\mathrm{E}\left(\mathrm{R}_{\mathrm{it}}\right)
$$

$\mathrm{AR}_{\mathrm{it}} \quad$ : i hissesinin $\mathrm{t}$ gününde hesaplanan anormal getirisini,

$\mathrm{R}_{\mathrm{it}} \quad$ : i hissesinin $\mathrm{t}$ gününde hesaplanan gerçekleşen (fiili) getirisini ve

$\mathrm{E}\left(\mathrm{R}_{\mathrm{it}}\right)$ : i hissesinin $\mathrm{t}$ günündeki normal (beklenen) getirisini ifade etmektedir.

Anormal getirilerin hesaplanabilmesi için, öncelikle fiili getirilerin ve beklenen getirilerin hesaplanması gerekir. Getiri dağılımlarının normal dağılıma yaklaştırılmasını sağlamak amacıyla fiili ve beklenen getiriler logaritmik olarak hesaplanmıştır.

$$
\mathrm{R}_{\mathrm{it}}=\ln \left(\frac{p_{i, t}}{P_{\mathrm{i}, t}-1}\right)
$$




$$
\begin{aligned}
& \mathrm{P}_{\mathrm{i}, \mathrm{t}} \quad \text { : i hissesinin t günündeki kapanış fiyatını, } \\
& \mathrm{P}_{\mathrm{i}, \mathrm{t}-1} \quad: \text { i hissesinin t-1 günündeki kapanış fiyatını ifade etmektedir. }
\end{aligned}
$$

Anormal getirilerin ölçülmesinde istatistiksel ve ekonomik modeller kullanılmaktadır. İstatistiksel modeller, herhangi bir ekonomik teoriye dayanmayan ve fiyat davranışları konusundaki istatistiki varsayımlardan ortaya çıkan modellerdir. Bu modeller, sabit ortalama getiri modeli, piyasa modeli ve faktör modelleridir. Ekonomik modeller ise, sermaye varlıklarını fiyatlama modeli (CAPM) ve arbitraj fiyatlama modelidir (Koçyiğit ve Kılıç, 2008). Bu çalışmada tercih edilen model sermaye varlıklarını fiyatlama modelidir. Buna göre;

$$
\mathrm{E}\left(\mathrm{R}_{\mathrm{it}}\right)=\mathrm{R}_{\mathrm{f}, \mathrm{t}}+\beta_{\mathrm{i}}\left(\mathrm{R}_{\mathrm{mt}}-\mathrm{R}_{\mathrm{f}, \mathrm{t}}\right)
$$

$\mathrm{R}_{\mathrm{f}, \mathrm{t}} \quad$ : $\mathrm{t}$ günü için risksiz faiz oranını,

$\mathrm{R}_{\mathrm{m}, \mathrm{t}} \quad$ : t günündeki piyasa getirisini (BİST TUM Endeksinin getirisini),

$\beta_{\mathrm{i}} \quad$ : i hisse senedinin sistematik riskini ifade etmektedir.

$\mathrm{T}$ günü için risksiz faiz oranı, iki yıl vadeli devlet tahvilinin faizi günlük faize çevrilerek hesaplanmıştır. Hisse senetlerinin sistematik riskini ifade eden beta $(\beta)$ katsayıları, olayın gerçekleştiği tarihten 11. gün öncesi ile 252 gün öncesindeki dönem için hisse getirisinin bağımlı, BİST TUM endeksi getirisinin bağımsız değişken olarak yer aldığı regresyon modelinden elde edilen katsayıdır. T günündeki piyasa getirisi de denklem 4'de gösterildiği şekilde hesaplanmıştır.

$$
\mathrm{R}_{\mathrm{mt}}=\ln \left(\frac{P_{m, t}}{P_{m, t-1}}\right)
$$

$\mathrm{P}_{\mathrm{m}, \mathrm{t}} \quad$ : BİST TUM endeksinin $\mathrm{t}$ günündeki kapanış değerini,

$\mathrm{P}_{\mathrm{m}, \mathrm{t}-1}$ : BİST TUM endeksinin t-1 günündeki kapanış fiyatını ifade etmektedir.

Her bir hisse senedi için olay penceresi içerisindeki her bir gün için beklenen ve gerçekleşen getiriler belirlendikten sonra denklem 1'de gösterilen şekilde anormal getiriler hesaplanabilecektir. Anormal getiriler kullanılarak denklem 5'de yer alan şekilde kümülatif anormal getirilerin (CAR) hesaplanması mümkündür. 


$$
\mathrm{CAR}_{\mathrm{t} 1}^{\mathrm{t} 2}=\sum_{\mathrm{t} 1}^{\mathrm{t} 2} \mathrm{AR}_{\mathrm{i}}
$$

Denklemde yer alan t1 ve t2 değerleri, kümülatif anormal getirilerin hesaplanacağ olay pencerelerini ifade etmekte ve çalışmada sırasıyla $(-10,+10),(-5,+5),(-1,+1),(-10,0)$, $(-5,0),(-1,0),(0,+1),(0,+5)$ ve $(0,+10)$ dönemlerini kapsamaktadır. Çalışmada anormal getiriler ve kümülatif anormal getiriler hesaplandıktan sonra $t$ testi uygulanarak anlamlılıkları sınamıştır.

Kümülatif anormal getirilerin sıfır olduğu hipotezinin reddedilmesi, diğer bir ifadeyle hesaplanan anormal getirilerin istatistiksel olarak anlamlı olduğunun kabul edilmesi durumunda; şirketlerin pay geri alım programı bildirimlerinin firmaların hisse fiyatlarında meydana gelen değişim üzerinde etkili ve bu değişimi açıklayıcı bir faaliyet olduğu sonucuna varılacaktır. Ayrıca çalışma sonucunda elde edilecek CAR değerleri, literatürde yer bulan çalışmalar temel alınmak suretiyle aşağıdaki yorumların yapılmasına imkân verecektir (Bozkurt, Öksüz ve Karakuş, 2015):

(1) Eğer sadece pay geri alım programı bildirimlerinin yapıldı̆̆ tarih öncesinde anormal getirilerin elde edildiği tespit edilirse, bu durumun; (i) içeriden öğrenilen bilgiler ile işlem yapıldığını, (ii) piyasanın tam etkin olmadığını veya (iii) bu anomalinin, piyasadaki söylenti ticareti etkisi ile gerçekleştiğini ortaya koyduğu kabul edilir.

(2) Eğer sadece pay geri alım programı bildirimlerinin yapıldığ 1 tarih sonrasında anormal getirilerin elde edildiği tespit edilirse, bu durumun; (i) piyasanın yarı etkin formda bile etkin piyasa olmadığını ve (ii) bu anomalinin, yatırımcıların, şirketlerin pay geri alım programlarına aşırı tepki vermesiyle gerçekleştiğini ortaya koyarak piyasada aşırı reaksiyon etkisinin var olduğunu ortaya koyduğu kabul edilir.

(3) Eğer pay geri alım programı bildirimlerinin yapıldığ 1 tarihin hem öncesinde hem de sonrasında anormal getirilerin elde edildiği tespit edilirse, bu durumun; (i) piyasanın yarı etkin formda bile etkin piyasa olmadığını ve (ii) bu anomalinin, hem söylenti ticareti hem de aşırı reaksiyon etkisiyle gerçekleştiğini ortaya koyduğu kabul edilir.

(4) Eğer pay geri alım programı bildirimlerinin yapıldığı tarihin hem öncesinde hem de sonrasında anormal getirilerin elde edilemediği tespit edilirse, bu durumun; piyasanın tam ya da en azından yarı etkin piyasa olduğunu ve piyasada anomalinin olmadığını ortaya koyduğu kabul edilir.

\section{BULGULAR}

Bu çalışmada pay geri alımı programı başlatılacağına ilişkin bildirimlerin ilgili hisse senetleri için anormal getiri yaratıp yaratmadığı incelenmiştir. Çalışmada kullanılan 20142016 yılları arasındaki bildirimlerin $(-10,+10)$ gün olay penceresi içerisinde yarattığı anormal 
getiriler ortalama olarak Şekil 2'de sunulmuştur. Şekil 2'de ortalama anormal getirilerin olayın gerçekleşme gününden 2 gün öncesinden itibaren pozitif anormal getiriler yaratmaya başladığı görülmektedir. Bildirim gerçekleştiği (0) gününde anormal getirilerin en yüksek düzeye ulaştığ1 ve bu tarihten sonra ise anormal getirilerin önemsiz seviyelere düştüğü gözlemlenmektedir.

Şekil 2. Olay Penceresi İçerisinde Günlük Ortalama Anormal Getiriler

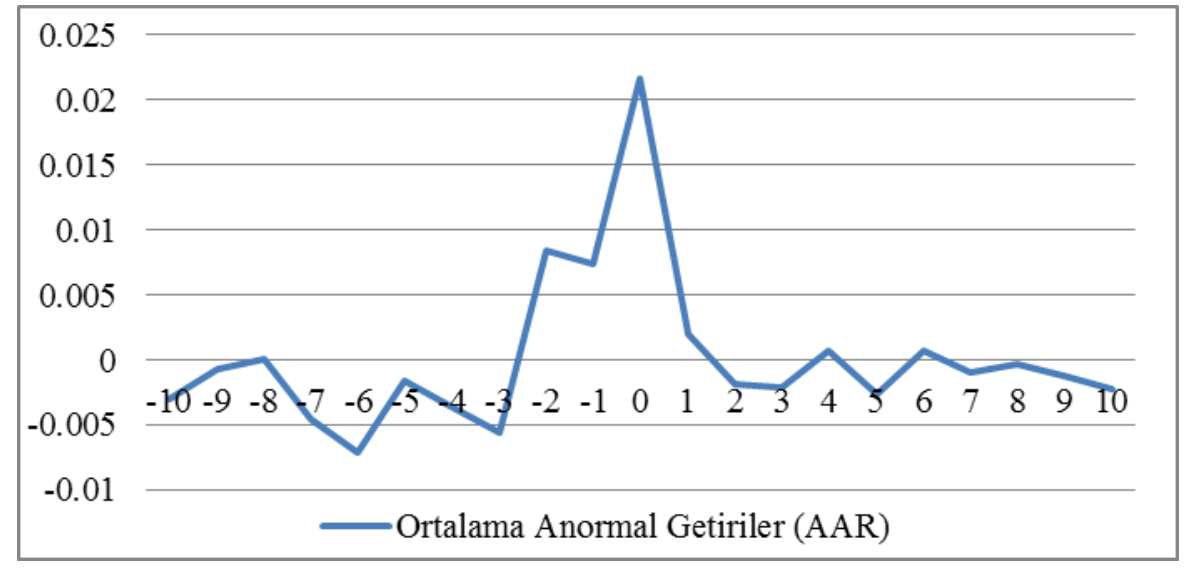

Tüm örneklem için elde edilen ortalama anormal getiriler ve ortalama kümülatif anormal getiriler Tablo 1'de sunulmuştur. Pay geri alım programına ilişkin bildirim yapılmadan 10 gün öncesi ile 3 gün öncesi arasında bir gün haricinde anormal getirilerin negatif olduğu görülmektedir. Bu da şirketlerin payların düşük değerlenmesi nedeniyle geri alım yaptıkları fikrini desteklemektedir. Ancak bu günlerde ortaya çıkan negatif anormal getiriler sadece (-6) ve (-3) günleri için istatistiksel olarak anlamlıdır. Bildirimin yapılmasından 2 gün önce, 1 gün önce ve bildirimin yapıldı̆̆ gün anormal getirilerin pozitif ve istatistiksel olarak anlamlı olduğu görülmektedir. Bildirimden önceki 2 gün elde edilen anormal getiriler sırasıyla binde 8 ve 7 gibi küçük düzeylerde gerçekleşirken, bildirimin yapıldığg gün yaklaşık yüzde 2,17'lik bir anormal getiri sağlandığı görülmektedir. Bildirim gerçekleştikten sonraki günlerde ise anormal getirilerin pozitif ve negatif değerler aldığ bildirimin yapıldığı günle kıyaslandığında göreceli olarak çok düşük gerçekleştikleri ve istatistiksel olarak anlamlı olmadıkları sonucuna varılmaktadır.

Tablo 1'de tüm örneklem için ortalama kümülatif anormal getiriler de yer almaktadır. $(-5,+5),(-1,+1),(0,+1),(0,+5),(0,+10),(0,-1)$ ve $(0,-5)$ olay pencerelerinin tamamı için pozitif kümülatif anormal getiriler oluştuğu ve bu getirilerin istatistiksel olarak anlamlı olduğu görülmektedir. Olay pencereleri içerisinde en yüksek anormal getiriyi sağlayan $(-1,+1)$ olay penceresidir. Bildirimin yapıldığı tarihten bir gün önce hisseye yatırım yapan bir yatırımcının bildirimin yapılmasından sonraki güne kadar hisseyi elinde bulundurması beklenen getiriden yaklaşık $\% 3$ daha fazla getiri sağlaması mümkün olacaktır. Bildirimin 
yapıldığ 1 tarihten hem önce hem de sonrasinda kümülatif anormal getiri elde edilebilecek olması söylenti ticareti ve aşırı reaksiyon etkilerinin varlı̆̆ını, piyasanın yarı etkin formda dahi etkin olmadığını göstermektedir.

Tablo 1. Tüm Örneklem İçin Ortalama Anormal ve Kümülatif Anormal Getiriler

\begin{tabular}{|c|c|c|}
\hline Olay Günleri & $A A R$ & t değgeri \\
\hline-10 & -0.002951 & -1.342412 \\
\hline-9 & -0.000688 & -0.226401 \\
\hline-8 & $9.90 \mathrm{e}-05$ & 0.045694 \\
\hline-7 & -0.004557 & -1.650187 \\
\hline-6 & -0.007153 & $-2.244892 * *$ \\
\hline-5 & -0.001626 & -0.613604 \\
\hline-4 & -0.003603 & -1.209128 \\
\hline-3 & -0.005539 & $-2.228483^{* *}$ \\
\hline-2 & 0.008468 & $2.113103 * *$ \\
\hline-1 & 0.007399 & $2.678255^{*}$ \\
\hline 0 & 0.021650 & $4.510515^{*}$ \\
\hline+1 & 0.002025 & 0.634310 \\
\hline+2 & -0.001815 & -0.745174 \\
\hline+3 & -0.002102 & -0.954727 \\
\hline+4 & 0.000778 & 0.299579 \\
\hline+5 & -0.002586 & -1.487313 \\
\hline+6 & 0.000716 & 0.279259 \\
\hline+7 & -0.000943 & -0.473735 \\
\hline+8 & -0.000325 & -0.194779 \\
\hline+9 & -0.001251 & -0.833084 \\
\hline+10 & -0.002197 & -0.909710 \\
\hline Olay Penceresi & $A C A R$ & $t$ değeri \\
\hline$(-10,+10)$ & 0.004243 & 0.413683 \\
\hline$(-5,+5)$ & 0.023423 & $2.682416^{*}$ \\
\hline$(-1,+1)$ & 0.030917 & $4.698790^{*}$ \\
\hline$(0,+1)$ & 0.023892 & $4.202011^{*}$ \\
\hline$(0,+5)$ & 0.018122 & $2.330154 * *$ \\
\hline$(0,+10)$ & 0.014022 & $1.675235^{* * * *}$ \\
\hline$(0,-1)$ & 0.028416 & $4.979952 *$ \\
\hline$(0,-5)$ & 0.026692 & $3.941898^{*}$ \\
\hline$(0,-10)$ & 0.011613 & 1.458004 \\
\hline
\end{tabular}

Tespit edilen anormal getirilerin farklı aktif büyüklükler için nasıl şekillendiği de ayrıca incelenmiştir. Aktif büyüklüğü 500 milyon TL'nin altında ve üstünde olan şirketler tarafindan yapılan bildirimlerin yarattığı anormal getiriler ayrı olarak ele alınmış ve sonuçlar Tablo 2'de gösterilmiştir. Örneklemi oluşturan toplam 100 bildirimin 54'ünün aktif büyüklüğü 500 milyon TL'nin altında olan şirketler tarafindan, 46'sının ise aktif toplamı 500 milyon TL'den fazla olan şirketler tarafindan yapıldığı tespit edilmiştir. Küçük şirketler için bildirim yapılmadan 4, 6 ve 7 gün önce negatif anormal getiriler oluştuğu ve bu getirilerin istatistiksel olarak anlamlı olduğu görülmektedir. Büyük şirketler için ise bildirim öncesindeki sadece 3. gün oluşan negatif anormal getirinin anlamlı olduğu sonucuna varılmıştır. Yine 
küçük şirketler için bildirim yapılmadan 1 ve 2 gün önce yaklaşık yüzde 1 seviyesinde pozitif ve anlamlı anormal getiriler elde edildiği, bu durumun büyük şirketler için ise geçerli olmadığı izlenmiştir. Bu durum bildirimlere ilişkin bilgilerin küçük şirketler için yatırımcılar tarafından önceden öğrenildiği tespitine neden olmaktadır. Bildirimin yapıldığı gün gerek küçük gerekse büyük şirketler için pozitif ve anlamlı anormal getirilerin oluştuğu ancak küçük şirketler için söz konusu anormal getirilerin daha yüksek olduğu görülmektedir. Yani aşırı reaksiyon etkisinin küçük şirket hisselerinde daha yüksek olduğu söylenilebilir. Kümülatif anormal getiriler küçük şirketler için $(-5,+5)$ olay penceresi içerisinde yer alan farklı olay pencerelerinde anormal getiri elde etmenin istatistiksel olarak mümkün olduğunu gösterirken büyük şirketler için bu olanak sadece $(-1,+1)$ aralığı ile sınırlıdır. Yani büyük şirketlerde pay geri alım bildirimlerinin etkisinin daha az ve kısa süreli olduğu görülmektedir.

Tablo 2. Aktif Büyüklüğe Göre Karşılaştırmalı Ortalama Anormal ve Kümülatif Anormal Getiriler

\begin{tabular}{|c|c|c|c|c|c|}
\hline \multicolumn{3}{|c|}{$\begin{array}{c}\text { Aktif Büyüklüğü } 500 \text { Milyon TL’den } \\
\text { Küçük Şirketler İçin }\end{array}$} & \multicolumn{3}{|c|}{$\begin{array}{c}\text { Aktif Büyüklüğü } 500 \text { Milyon TL'den } \\
\text { Büyük Şirketler İçin }\end{array}$} \\
\hline $\begin{array}{c}\text { Olay } \\
\text { Günleri }\end{array}$ & $A A R$ & t değgeri & $\begin{array}{c}\text { Olay } \\
\text { Günleri }\end{array}$ & $A A R$ & t de ğgeri \\
\hline-10 & -0.001499 & -0.488155 & -10 & -0.004923 & -1.571488 \\
\hline-9 & -0.003949 & -0.941070 & -9 & 0.004172 & 0.984136 \\
\hline-8 & 0.000292 & 0.080557 & -8 & -0.000946 & -0.440399 \\
\hline-7 & -0.009047 & $-1.973164 * * *$ & -7 & -0.000290 & -0.118697 \\
\hline-6 & -0.011204 & $-2.303862 * *$ & -6 & -0.001042 & -0.261811 \\
\hline-5 & 0.000128 & 0.031658 & -5 & -0.003510 & -1.058813 \\
\hline-4 & -0.007810 & $-2.011242 * *$ & -4 & 0.002158 & 0.473602 \\
\hline-3 & -0.005672 & -1.489228 & -3 & -0.006490 & -2.069773 **1 \\
\hline-2 & 0.014017 & $2.424505^{* * *}$ & -2 & 0.001908 & 0.354844 \\
\hline-1 & 0.013695 & $3.248912 *$ & -1 & -0.000430 & -0.141945 \\
\hline 0 & 0.023420 & $3.169451 *$ & 0 & 0.018803 & $3.215953 *$ \\
\hline+1 & 0.001371 & 0.278556 & +1 & 0.002828 & 0.726788 \\
\hline+2 & 0.000124 & 0.031505 & +2 & -0.003564 & -1.371418 \\
\hline+3 & 0.000388 & 0.110623 & +3 & -0.005514 & $-2.250876^{\text {**: }}$ \\
\hline+4 & 0.000809 & 0.275949 & +4 & 0.001388 & 0.311591 \\
\hline+5 & -0.004964 & $-1.897442 * * *$ & +5 & 0.000109 & 0.050870 \\
\hline+6 & -0.001363 & -0.334723 & +6 & 0.003008 & 1.047609 \\
\hline+7 & -0.000612 & -0.202517 & +7 & -0.001493 & -0.596992 \\
\hline+8 & 0.000153 & 0.069261 & +8 & -0.001247 & -0.484933 \\
\hline+9 & -0.000322 & -0.140222 & +9 & -0.001525 & -0.792280 \\
\hline+10 & -0.000607 & -0.154045 & +10 & -0.004377 & -1.753411 \\
\hline $\begin{array}{c}\text { Olay } \\
\text { Penceresi }\end{array}$ & $A C A R$ & t dĕğeri & $\begin{array}{c}\text { Olay } \\
\text { Penceresi }\end{array}$ & $A C A R$ & t de $\breve{g} e r i$ \\
\hline$(-10,+10)$ & 0.007346 & 0.472682 & $(-10,+10)$ & 0.000600 & 0.046178 \\
\hline$(-5,+5)$ & 0.035504 & $2.683433^{*}$ & $(-5,+5)$ & 0.009240 & 0.864100 \\
\hline$(-1,+1)$ & 0.038485 & $3.840610 *$ & $(-1,+1)$ & 0.022032 & $2.733297 *$ \\
\hline$(0,+1)$ & 0.024790 & $2.860085^{*}$ & $(0,+1)$ & 0.022838 & $3.207378^{*}$ \\
\hline$(0,+5)$ & 0.021146 & 1.716511 *** & $(0,+5)$ & 0.014572 & 1.640254 \\
\hline$(0,+10)$ & 0.018395 & 1.365400 & $(0,+10)$ & 0.008887 & 0.975442 \\
\hline$(0,-1)$ & 0.037114 & $4.386373^{*}$ & $(0,-1)$ & 0.018205 & $2.513902 * *$ \\
\hline$(0,-5)$ & 0.037777 & $3.848667 *$ & $(0,-5)$ & 0.013679 & 1.537936 \\
\hline$(0,-10)$ & 0.012370 & 1.020294 & $(0,-10)$ & 0.010723 & 1.071658 \\
\hline
\end{tabular}


Çalışmada farklı piyasa değeri/ defter değerine (PD/DD) sahip şirketler için pay geri alım bildirimlerinin etkisi de karşılaştırılmıştır. PD/DD 1.5'ten daha küçük olan şirketler tarafından yapılan 63 bildirimin ve PD/DD 1.5'ten büyük olan şirketler tarafından yapılan 37 bildirimin hisse getirileri üzerindeki etkisi karşılaştırmalı olarak Tablo 3'de sunulmuştur. PD/DD oranı düşük şirketler tarafından yapılan bildirimlerin, bildirim tarihinde daha yüksek anormal getiri yarattığı gözlemlenmiştir. Ayrıca yüksek PD/DD oranına sahip şirketlerde bildirim yapılmadan 2 gün önce yaklaşık yüzde 1.32'lik bir anormal getiri oluştuğu tespit edilmiştir. Kümülatif anormal getiriler ise iki grup arasında önemli farklılıklar içermektedir. Küçük PD/DD oranlı şirketlerde bildirimler $(-5,+5)$ aralığındaki farklı olay pencerelerinin tamamında anlamlı ve pozitif anormal getirilerek görülürken, yüksek PD/DD olan şirketlerde kümülatif anormal getirilerin $(0,-1),(0,-5),(0,-10)$ ve $(-1,+1)$ olay pencerelerinde pozitif ve anlamlı olduğu sonucuna ulaşılmıştır. Yani PD/DD oranı yüksek işletmelerde bildirimin etkisinin bildirim yapılmadan önceki günlerde de var olduğu görülmektedir.

Tablo 3. PD/DD Oranına Göre Karşılaştırmalı Ortalama Anormal ve Kümülatif Anormal Getiriler

\begin{tabular}{|c|c|c|c|c|c|}
\hline \multicolumn{3}{|c|}{$\begin{array}{l}\text { PD/DD Oranı 1.5'den Küçük Olan } \\
\text { Şirketler İçin }\end{array}$} & \multicolumn{3}{|c|}{$\begin{array}{l}\text { PD/DD Oranı 1.5'den Büyük Olan } \\
\text { Şirketler İçin }\end{array}$} \\
\hline $\begin{array}{c}\text { Olay } \\
\text { Günleri }\end{array}$ & $A A R$ & t dĕgeri & $\begin{array}{c}\text { Olay } \\
\text { Günleri }\end{array}$ & $A A R$ & t dĕgeri \\
\hline-10 & -0.007184 & $-2.489121 * *$ & -10 & 0.002976 & 0.931367 \\
\hline-9 & -0.003987 & -1.035725 & -9 & 0.006021 & 1.289394 \\
\hline-8 & 0.002091 & 0.715956 & -8 & -0.003660 & -1.203025 \\
\hline-7 & -0.006017 & -1.531825 & -7 & -0.002791 & -0.864661 \\
\hline-6 & -0.005721 & -1.459120 & -6 & -0.007618 & -1.324131 \\
\hline-5 & -0.005328 & $-1.870494 * * *$ & -5 & 0.005128 & 0.991619 \\
\hline-4 & -0.001759 & -0.464671 & -4 & -0.005884 & -1.201609 \\
\hline-3 & -0.008413 & $-2.666824 *$ & -3 & -0.000765 & -0.193737 \\
\hline-2 & 0.005566 & 1.114764 & -2 & 0.013221 & $1.957160 * * *$ \\
\hline-1 & 0.006597 & $2.227002 * *$ & -1 & 0.007024 & 1.255892 \\
\hline 0 & 0.025351 & $4.036683 *$ & 0 & 0.013895 & $1.901166^{* * * *}$ \\
\hline+1 & 0.005014 & 1.209466 & +1 & -0.001828 & -0.389712 \\
\hline+2 & 0.000141 & 0.040877 & +2 & -0.004671 & -1.624766 \\
\hline+3 & -0.001867 & -0.627805 & +3 & -0.002994 & -0.933094 \\
\hline+4 & 0.001535 & 0.439219 & +4 & 0.000264 & 0.072015 \\
\hline+5 & -0.000286 & -0.152040 & +5 & -0.007059 & -2.172348 \\
\hline+6 & 0.002306 & 1.057170 & +6 & -0.002483 & -0.423040 \\
\hline+7 & -0.001690 & -0.640421 & +7 & 0.000173 & 0.057967 \\
\hline+8 & -0.001121 & -0.513401 & +8 & 0.001046 & 0.405454 \\
\hline+9 & -0.000509 & -0.251426 & +9 & -0.002501 & -1.157819 \\
\hline+10 & -0.002938 & -0.860930 & +10 & -0.001301 & -0.430650 \\
\hline $\begin{array}{c}\text { Olay } \\
\text { Penceresi }\end{array}$ & $A C A R$ & t dĕğeri & $\begin{array}{c}\text { Olay } \\
\text { Penceresi }\end{array}$ & $A C A R$ & t değgeri \\
\hline$(-10,+10)$ & 0.003097 & 0.221507 & $(-10,+10)$ & 0.006193 & 0.429118 \\
\hline$(-5,+5)$ & 0.027587 & $2.487204 * *$ & $(-5,+5)$ & 0.016331 & 1.144229 \\
\hline$(-1,+1)$ & 0.037862 & $4.474923 *$ & $(-1,+1)$ & 0.019091 & $1.857102 * * *$ \\
\hline$(0,+1)$ & 0.030837 & $4.091573^{*}$ & $(0,+1)$ & 0.012067 & 1.468199 \\
\hline$(0,+5)$ & 0.030170 & $2.998114 *$ & $(0,+5)$ & -0.002392 & -0.206598 \\
\hline$(0,+10)$ & 0.026637 & $2.420726 * *$ & $(0,+10)$ & -0.007458 & -0.618768 \\
\hline$(0,-1)$ & 0.032819 & $4.579539 * *$ & $(0,-1)$ & 0.020919 & $2.218484 * *$ \\
\hline
\end{tabular}




\begin{tabular}{|c|c|c|c|c|c|}
\hline$(0,-5)$ & 0.023212 & $2.900782 *$ & $(0,-5)$ & 0.032618 & $2.650248 * *$ \\
\hline$(0,-10)$ & 0.002255 & 0.232501 & $(0,-10)$ & 0.027546 & $2.028330^{* * * *}$ \\
\hline
\end{tabular}

\section{SONUÇ}

$\mathrm{Bu}$ çalışmada, şirketlerin pay geri alım programı ilanlarının hisse getirileri üzerinde etkisi olay çalışması yöntemi ile araştırılmıştır. BİST’te listelenen şirketlere ait 2014-2016 döneminde 100 adet pay geri alım programına ilişkin bildirim tespit edilmiştir. İlgili bildirimlerin şirketlerin hisse senetlerinde bildirim tarihinden 10 gün önce ve 10 gün sonras1 dönem için ortaya çıkan anormal getiriler kullanılarak bildirimlerin etkisi test edilmiştir.

Analiz sonuçlarına göre, pay geri alımına ilişkin bildirimlerin yapıldı̆̆ iki gün önce sınırlı olmakla birlikte pozitif ve anlamlı anormal getiriler elde edildiği görülmüştür. Olay gününde ise yaklaşık yüzde 2'lik ve istatistiksel olarak anlamlı anormal getiri tespit edilmiştir. Kümülatif anormal getiriler ise $(-5,+5),(-1,+1),(0,+1),(0,+5),(0,+10)$, $(0,-1)$ ve $(0,-5)$ olay pencerelerinin tamamı için pozitif ve anlamlı olarak tespit edilmiştir. Söz edilen aralıkların herhangi bir tanesi için ilgili hisse senetlerine yatırım yapan yatırımcıların beklenen getirinin üzerinde bir getiri elde edebilecekleri görülmektedir. Bu nedenle piyasada söylenti ticareti ve aşırı reaksiyon etkilerinin varlığı, piyasanın yarı etkin formda dahi etkin olmadığını görüşü desteklenmiş olmaktadır.

Çalışmada ayrıca pay geri alım bildirimlerinin hisse getirisine etkisi büyük-küçük şirket ayrımı ve PD/DD oranı yüksek-düşük ayrımı yapılarak karşılaştırmalı olarak da değerlendirilmiştir. Büyük şirketler tarafından yapılan bildirimlerin daha kısa bir dönem için ve daha düşük anormal getiriler yarattığı sonucuna varılmıştır. PD/DD yüksek şirketler tarafından yapılan bildirimlerin bildirim tarihinden önce kümülatif anormal getiriler yarattığ da çalışmada ulaşılan bir diğer sonuçtur.

Pay geri alımının Türkiye piyasası için yeni bir uygulama olması nedeniyle bu çalışma, pay geri alımlarının sadece kısa dönemli etkilerine odaklanmıştır. İlerleyen dönemlerde veri döneminin uzaması mümkün olacağından yapılacak çalışmalarda pay geri alım programlarının hisse senetlerinin uzun dönemli performansına etkisinin değerlendirilmesi literatüre önemli katkı sağlayacaktır.

\section{KAYNAKLAR}

Albaity, Mohamed \& Said Diana Syafiza (2016), “Impact of Open-Market Share Repurchases on Long-Term Stock Returns: Evidence From the Malaysian Market”,SAGE Open, 6(4), pp. 1-12.

Andriosopoulos Dimitris \& Lasfer Meziane (2015), "The market valuation of share repurchases in Europe", Journal of Banking \& Finance, 55, pp. 327-339. 
Bozkurt, İbrahim, Öksüz, Sezer \& Karakuş, Rıfat (2015), "Finansal Tablo İlanlarının Hisse Getirileri Üzerindeki Etkisi: BİST'de Ampirik Bir Uygulama", Maliye Finans Yazıları, 29(103), ss. 113-140.

Chang, Shao-Chi, Chen Sheng-Syan \& Chen, Li-Yu (2010), "Does prior record matter in the wealth effect of open-market share repurchase announcements?", International Review of Economics and Finance, 19, pp. 427-435.

Chatterjee, Chanchal \& Dutta, Paromita (2015), “Anomalous Price Behaviour around Open Market Stock Repurchase Announcements in India”, The Journal for Decision Makers, 40(4), pp. 435-443.

Dann Larry Y. (1981), “Common Stock Repurchases: An Analysis of Returns to Bondholders and Stockholders", Journal of Financial Economics, 9, pp. 113-138.

Dittmar, Amy K. (2000). "Why do firms repurchase stock?", The Journal of Business, 73(3), pp. 331-355.

Dolley, James C. (1933), “Common Stock Split-Ups Motives and Effects”, Harvard Business Review, 12(1), pp. 70-81.

Eyüboğlu, Kemal \& Bulut, Halil İbrahim (2015), “The Effects Of Financial News On Stock Performance: Case Of BIST-30 Companies", Journal of Economics, Finance and Accounting, 2(1), pp. 75-88.

“Geri Alınan Paylar Tebliği (II-22.1)”, Resmi Gazete, 28871 (3/1/2014).

Gökgöz, Ahmet (2014), "Hisse Senedi Geri Alımı ve Muhasebesi”, Muhasebe ve Vergi Uygulamaları Dergisi, 7(2), 1-14.

Grullon, Gustavo \& Michaely, Roni (2004), “The Information Content of Share Repurchase Programs", The Journal of Finance, 59(2), 651-680.

Isa, Mansor \& Lee, Siew-Peng (2014), "Market Reactions To Share Repurchase Announcements in Malaysia", Asian Academy of Management Journal of Accountıng And Finance, 10(1), 45-73.

Kahle, Kathleen M. (2002), "When a buyback isn't a buyback: Open market repurchases andemployee options", Journal of Financial Economics, 63, 235-261.

Kaval, Hasan (2016), “Geri Alınan Payların Vergilemesinde ve Muhasebesinde Sorunlar", Gazi İktisat ve İşletme Dergisi, 2(2), 87-116.

Koçyiğit, Murat \& Kılıç, Asiye (2008), "Leasing Sektöründe KDV Oranı Değişikliğinin IMKB'de İşlem Gören Leasing Şirketlerinin Hisse Senedi Getirisine Etkisi”, Muhasebe ve Finansman Dergisi, 40, 165-174.

Lee Chun I., Ejara Demissew Diro \& Gleason Kimberly C. (2010), “An empirical analysis of European stock repurchases", Journal of Multinational Financial Management, 20( 23), pp. 114-125. 
Manconi, Alberto, Peyer, Urs \& Vermaelen, Theo (2014), "Buybacks Around the World", European Corporate Governance Institute (ECGI) - Finance Working Paper No. 436/2014, DOI: 10.2139/ssrn.2330807.

Pirgaip, Burak (2014) "Pay Geri Alımları İle Geri Alım İşlemlerinin Neden Ve Sonuçlarının Analizi: Borsa İstanbul Üzerine Bir Uygulama", Yayımlanmamış Doktora Tezi, Hacettepe Üniversitesi Sosyal Bilimler Enstitüsü.

Pirgaip, Burak \& Karacaer, Semra (2015), "Borsa Şirketlerinin Pay Geri Alım İşlemlerine Yönelik TMS/TFRS Uygulamaları", Muhasebe ve Finansman Dergisi, 66, 105-128.

"Sermaye Piyasas1 Kanunu (6362 S.K.)", Resmi Gazete, 28513 (30/12/2012).

Su, Nai-Hui \& Lin, Chan-Jane (2012), "The Impact of Open-Market Share Repurchases on Long-Term Stock Returns: Evidence from the Taiwanese Market", Emerging Markets Finance \& Trade, 48(Supplement 2), 200-229.

“Türk Ticaret Kanunu (6762 S.K.)”, Resmi Gazete, 9353 (29/06/1956).

“Türk Ticaret Kanunu (6102 S.K.)”, Resmi Gazete, 27846 (13/1/2011).

Wesson, N., Muller, C. \& Ward, M. (2014), "Market underreaction to open market share repurchases on the JSE", South African Journal of Business Management, 45(4), 5969. 